\title{
Educational Counselors' Self-efficacy and Professional Competence
}

\author{
Ali Saleh Jarwan ${ }^{1}$, Basem Mohammed Al-frehat ${ }^{2, *}$ \\ ${ }^{1}$ Department of Counseling and Educational Psychology, Yarmouk University, Jordan \\ ${ }^{2}$ Department of Educational Science, Al-Balqa`Applied University, Jordan
}

Received November 5, 2019; Revised December 9, 2019; Accepted December 17, 2019

Copyright $(2020$ by authors, all rights reserved. Authors agree that this article remains permanently open access under the terms of the Creative Commons Attribution License 4.0 International License

\begin{abstract}
The current study aimed to identify educational counselors' self-efficacy and professional competence in Ajloun Governorate of Jordan. It also investigated the extent to which such self-efficacy and professional competence may differ according to three variables: educational counselors' gender, the school stage and the number of experience years. To achieve this, all 88 educational counselors working at public schools in Ajloun Governorate were investigated. The measure of self-efficacy made of 31 paragraphs and the measure of professional competence made of 27 paragraphs were applied to them. The statistical analysis of mean and standard deviations, the 3-WAY-ANOVA analysis, and simple regression showed that the degree of self-efficacy of educational counselors was medium. The response mean of the total score was 3.59 , whereas the degree of professional competence of educational counselors was high. The response mean of the total score was 3.76. Additionally, the results showed that there were no statistically significant differences, related to the degree of educational counselors' self-efficacy and professional competence, due to the educational counselors' gender or the school stage. The results also showed that there were statistically significant differences, related to the degree of educational counselors' self-efficacy and professional competence, due to the educational counselors' experience years for the benefit of those having (10-19) experience years. As well, the results of this study showed that there was a statistically positive impact between the degree of self-efficacy and that of professional competence of the educational counselors.
\end{abstract}

Keywords Self-efficacy, Professional Competence, Educational Counselors, Students, School

\section{Introduction}

Jordan is located in South-West Asia, and the Middle of the Levant is located in the southern part of the Levant, and the northern part of the Arabian Peninsula, with a population of $(10,538,923)$. And the Jordanian society is characterized by its youth, with an increasing proportion of young people [24]. Education in Jordan is one of the finest education systems in the world and plays a pivotal role in the life and culture of Jordanian society, with 2,400,000 students in schools. As a result of this steady increase in the number of students, the Ministry of Education has recruited mentors in schools, and the number of female mentors at the beginning of the first semester of the 2019/2018 academic year has reached (2021) male and female counselors as follows: 854 male educational counselors in male schools and 1,167 female educational counselors in female schools to help develop the personality of the student from all aspects of psychological, social, behavioral, professional and cognitive, to be an active citizen who contributes to the building of his society [25].

Psychological counseling and educational guidance are considered human and educational at the same time. The psychological counsellor plays an important role in achieving the general educational goals of building students' personality and developing their social, emotional, cognitive and moral development [2]. The psychological counsellor is the person who is responsible of the main operations of psychological counseling. Therefore, he/she should be self-sufficient and effective and have highly professional competence that enables him/her to perform his/her work successfully [5].

Self-efficacy and professional competence are important prerequisites for educational leadership in general and for educational counseling, in particular. The educational counsellor guides and solves students 'questions and develops students' beliefs about themselves to increase their ability to interact successfully with different life situations [19]. Self-efficacy is not just general feelings but an important assessment by the individual of what he/she can do, his/her perseverance and flexibility in dealing with difficult and complex situations, and his/her identification 
of difficulties and resistance to any failure in counseling work [11]. Al-Nashi [6] defines self-efficacy as the individual's expectations about his/her ability to solve questions and meet the new challenges that may affect the degree of optimism and positive perspective, so he/he is motivated to perform tasks.

In addition, the lack of professional competence of some educational workers, including educational counselors, results in a great burden. It is one factor behind staff's non-specialization, weakness of counseling effectiveness and sense of physical and psychological exhaustion, something which makes them unable to focus on the tasks assigned to them [14].

The concept of self-efficacy is one of the basic concepts introduced by Bandura's theory of personality in 1997. It refers to the individual's behavior of initiative and perseverance. It depends on the individual's judgments and expectations regarding his/her behavioral skills and their adequacy to deal successfully with the environment challenges and the surrounding circumstances [10]. In a related vein, the studies on self-efficacy were directed to three directions. The first direction investigates self-efficacy of professional selection and university specialization. This direction is associated with professional counseling and guidance. The second direction investigates self-efficacy's connection with teachers' teaching methods and practices and their impact on the final results achieved by students. The third direction explores the connection of students' self-efficacy with motivation constructs, academic performance, and students' learning achievement [18].

Bandura [12] noted that the strong sense of self-efficacy enhances the personality as well as mental health and supports human achievement. The Schunk [21] found that increasing students' self-efficacy leads to higher learning achievement. Hay [16] argued that individuals with low self-efficacy bear negative thoughts regarding their pre-assessment of tasks. Such individuals also have negative conceptual errors that negatively affect their memory performance and thinking through their pre-assessment of tasks. Tawfeeq [22] confirmed that there was a positive correlation between self-efficacy and the level of ambition and achievement. This study also argued that the individual's perception of himself/herself (i.e. awareness of his/her abilities and capabilities) is the basis of his/her ambitions and the reality of the work achievement necessary for such ambitions.

Based on theoretical indicators, the concept of self-efficacy is related to the concept of professional competence, given that self-efficacy represents the behavior of initiative, perseverance and the effort to achieve certain types of performance. Along these lines, Bandura explained that educational counselors' awareness of their own effectiveness is related to their assessment of their ability to achieve a certain level of achievement in addition to their ability to control events. Judgment of self-efficacy affects the nature of the objective they seek to achieve, the amount of effort they need to exert, and their thinking practice, which is ultimately reflected on educational counselors' professional competence of the performance of their counseling tasks [20].

Al-Yafi'i \& Al-Sheikh [9] defined professional competence as educational counselors' set of abilities which include skills and attitudes that are expressible in behavioral practices educational counselors exercise while performing educational tasks effectively and proficiently. Al-Sarrai [7] viewed professional competence as the ability of an individual to efficiently perform, achieve, and adapt to the nature of his/her profession.

It should be noted that an educational counselor who is sufficiently professional and self-effective in counseling helps to enhance the counselee's personality and lead to an effective modification of his/her behavior. The success of the entire counseling process depends crucially on the educational counselors' self-efficacy and competence in his/her use of counseling skills. The psychological counseling process and educational guidance are big responsibilities, so any performer of these two processes should be characterized by intelligence, experience and knowledge. Such characteristics improve the educational counselors' performance and increase their professional competence of counseling. Note that the personality of educational counselors consists of several important aspects, i.e. a scientific, technical, and professional aspect, an applied, and practical aspect, and a personal, subjective aspect which is related to the socio-psychological formation of educational counselors [15].

Upon the review of educational literature, we find some studies that examined self-efficacy and professional competence. For instance, Al-Harshasha [4] aimed to assess the professional competence of Jordanian educational counselors regarding the counseling interview from the perspectives of educational counselors, counselees, and the observer. The study sample consisted of (212) educational counselors and (335) counselees. The results of the study showed that educational counselors practice the skills and techniques of the counseling interview with a high degree of professionalism. The results also showed that educational counselors' nonverbal skills were better than their verbal skills.

Obaid [17] aimed at identifying the self-efficacy and its relation to educational counselors' psychological stability. The study sample consisted of (300) educational counselors from Baghdad Governorate-Iraq. The results of the study showed that the counselors are highly effective and have high psychological stability. The results also showed that there was a weak but not statistically significant correlation between self-efficacy and psychological stability.

Al-Daraji [3] aimed at identifying the level of self-efficacy and its relation to satisfaction with counseling work of educational counselors in Baghdad governorate. 
The study sample consisted of (150) educational counselors. The results showed that educational counselors suffer from clear decline related to the counseling self-efficacy. However, they are, to an acceptable extent, satisfied with counseling. The results also showed that there was a statistically-significant negative correlation between counseling self-efficacy and satisfaction with counseling work.

Al-Shurafa [8] aimed to investigate the self-efficacy of psychological counselors within educational counseling in Gaza Strip. The study sample consisted of (279) educational counselors in public schools of Gaza. The results of the study showed that the professional self-efficacy obtained a relative weight $(87.51 \%)$. The results also indicated that there were no statistically significant differences related to the professional self-efficacy of educational counselors according to sex, school stage, and educational region.

Tishyosh [23] aimed at identifying the counseling skills of the counseling trainees, as perceived by counseling trainees and co-counselors skills due to gender and the study program. The study sample consisted of (348) counseling trainees and 348 co-counselors. The results of the study showed that counseling skills of the study sample came to a medium degree of self-assessment and the co-counselors' assessment. The results of the study also showed that there were statistically significant differences related to counseling skills of the study sample due to self-assessment due to the gender variable for the benefit of females. The results of the study also showed that there were statistically significant differences due to the study program variable for the benefit of master's students for both preparation of counseling program and diagnosis and counseling. The results of the study also showed that there were statistically significant differences related to counseling skills of the study sample according to co-counselors' assessment due to gender for the benefit of males with respect to preparation of counseling program in addition to statistically significant differences due to the study program variable for the benefit of master's students for diagnosis and counseling.

As it appears, all the previous studies aimed to identify the self-efficacy and professional competence separately. Although this study is similar to the previous works in that it aims to identify the self-efficacy and professional competence of educational counselors, it is different from them in that it addresses self-efficacy and professional competence in the same study. Additionally, this works identifies the degree of difference of self-efficacy and professional competence of the counselors due to educational counselor's gender, and the school stage he/she works in, and the number of experience years.

\subsection{The Study Question}

The question of the current study was observed through the work of the authors of this work as educational counselors, as lecturers in the department of counseling and educational psychology, and as supervisors of field training student, whose major is psychological counseling. The authors observed that there are some cases of low professional competence and weakness of using counseling skills. The authors observed that that some counselors do not have good self-efficacy to perform their counseling role. This motivates the authors of this work to identify the questions that face these councellors in a scientific and practical manner, given that pertinent research did not address the relationship between the variables of the study, for the best knowledge of the researchers.

Hence, the question of the current study is determined by answering the following questions:

1. Does the degree of self- efficacy of educational counselors vary according to variables: the gender of the counselor, the stage of study, and the number of years of experience?

2. Does the degree of professional competence of educational counselors vary according to variables: the gender of the counselor, the stage of study, and the number of years of experience?

3. Is there a relationship between self-efficacy and professional competence among educational counselors?

\subsection{The Significance of the Study}

The educational counsellor is considered the best educator who can deal with the students' personality and understand his/her needs. He/she provides aid and assistance to students to achieve their psychological and social compatibility. Additionally, he/she solves educational, psychological and social questions and attempts to build students' personality successfully. $\mathrm{He} / \mathrm{she}$ plays a supporting role that helps teachers and school administration to reduce the questions related to students, whether such questions are related to the student himself/herself, his/her family, or teachers and school management. This great effort requires educational counselors to be highly effective, professional, and competent, so he/she is able to achieve the roles and tasks assigned to him/her.

This study is also important because it provides a database that could be benefited from by educational counselors in counseling work. It also develops two instruments that measure the self-efficacy and professional competence of educational counselors, which can help to identify their weaknesses, reveal their strong aspects. Such a database is a good source for educators who are responsible for the training of educational counselors. 


\subsection{The Study Objectives}

The current study seeks to identify the self-efficacy and professional competence of educational guides in Ajloun governorate, and to know the degree of difference according to the variables of the gender of the counselor, the stage of study, and the number of years of experience, in addition to revealing the relationship between self-efficacy and professional competence of the educational counselors.

\subsection{Definitions of the Main Concepts}

Self-efficacy: The individual's belief about his/her potential to produce specific levels of performance, which exert influence on the events that affect our life. It includes initiative, effort and perseverance [12]. It is procedurally defined as the overall degree obtained by an educational counsellor on the scale of self-efficacy used in this study.

Professional competence: readiness, ability and availability of necessary skills that qualify individuals to work [1]. It is procedurally defined as the total degree obtained by an educational counsellor on the scale of professional competence used in this study.

\section{Materials and Methods}

\subsection{The Subjects of the Study}

The total number of the subjects of the current study is (88) educational counselors who constitute the all educational counselors working in public schools of the Directorate of Education in Ajloun for the academic year 2017/2018. Table 1 shows the distribution of study subjects according to the study variables.

Table 1. Distribution of the study subjects according to the educational counsellor's gender, the school stage, and the number of experience years

\begin{tabular}{|c|c|c|c|c|c|}
\hline & & & \multicolumn{2}{|c|}{ Gender } & \multirow[b]{2}{*}{ Total } \\
\hline & & & Male & Female & \\
\hline \multirow{8}{*}{ School Type } & \multirow{4}{*}{ Primary } & Number & 12 & 39 & 51 \\
\hline & & $\%$ of school type & $23.5 \%$ & $76.5 \%$ & $100.0 \%$ \\
\hline & & $\%$ of gender & $36.4 \%$ & $70.9 \%$ & $58.0 \%$ \\
\hline & & $\%$ of total & $13.6 \%$ & $44.3 \%$ & $58.0 \%$ \\
\hline & \multirow{4}{*}{ Secondary } & Number & 21 & 16 & 37 \\
\hline & & $\%$ of school type & $56.8 \%$ & $43.2 \%$ & $100.0 \%$ \\
\hline & & $\%$ of gender & $63.6 \%$ & $29.1 \%$ & $42.0 \%$ \\
\hline & & $\%$ of total & $23.9 \%$ & $18.2 \%$ & $42.0 \%$ \\
\hline \multirow{4}{*}{ Total } & & Number & 33 & 55 & 88 \\
\hline & & $\%$ of school type & $37.5 \%$ & $62.5 \%$ & $100.0 \%$ \\
\hline & & $\%$ of gender & $100.0 \%$ & $100.0 \%$ & $100.0 \%$ \\
\hline & & $\%$ of total & $37.5 \%$ & $62.5 \%$ & $100.0 \%$ \\
\hline \multirow{12}{*}{ Number of experience years } & \multirow{4}{*}{ Less than 10 years } & Number & 6 & 17 & 23 \\
\hline & & $\%$ of experience years number & $26.1 \%$ & $73.9 \%$ & $100.0 \%$ \\
\hline & & $\%$ of gender & $18.2 \%$ & $30.9 \%$ & $26.1 \%$ \\
\hline & & $\%$ of total & $6.8 \%$ & $19.3 \%$ & $26.1 \%$ \\
\hline & \multirow{4}{*}{$(10-19)$ years } & Number & 17 & 18 & 35 \\
\hline & & $\%$ of experience years number & $48.6 \%$ & $51.4 \%$ & $100.0 \%$ \\
\hline & & $\%$ of gender & $51.5 \%$ & $32.7 \%$ & $39.8 \%$ \\
\hline & & $\%$ of total & $19.3 \%$ & $20.5 \%$ & $39.8 \%$ \\
\hline & \multirow{4}{*}{20 years and more } & Number & 10 & 20 & 30 \\
\hline & & $\%$ of experience years number & $33.3 \%$ & $66.7 \%$ & $100.0 \%$ \\
\hline & & $\%$ of gender & $30.3 \%$ & $36.4 \%$ & $34.1 \%$ \\
\hline & & $\%$ of total & $11.4 \%$ & $22.7 \%$ & $34.1 \%$ \\
\hline \multirow{4}{*}{ Total } & & Number & 33 & 55 & 88 \\
\hline & & $\%$ of experience years number & $37.5 \%$ & $62.5 \%$ & $100.0 \%$ \\
\hline & & $\%$ of gender & $100.0 \%$ & $100.0 \%$ & $100.0 \%$ \\
\hline & & $\%$ of total & $37.5 \%$ & $62.5 \%$ & $100.0 \%$ \\
\hline
\end{tabular}




\subsection{Study Instrument}

\subsubsection{Self-efficacy Scale}

The researchers developed the scale of self-efficacy through consulting related literature $[8,3,17]$. The scale consists initially of (33) paragraphs which are answered to in accordance with Likert's five-layer scale (very large, to a large degree, to a medium degree, to a low degree, very low). The following measure has been adopted to determine the mean rating: The mean of (2.33 and lower) got low degree; the mean of (234-3.66) got medium degree; the mean of (3.67 and higher) got high degree.

\subsubsection{The Scale Validity}

The researchers verified the validity of the scale through asking several arbitrators with high experience in the field of psychological counseling and educational psychology to judge the extent to which the paragraphs are related to the scale and whether the language of the scale is appropriate or not. According to the arbitrators, (4) paragraphs are reworded, while two paragraphs are deleted for lack of relevance to the study tool. This means that the final number of paragraphs of the scale is (31).

\subsubsection{Stability of the Scale}

To verify the stability of the scale, it was applied to a pilot sample consisting of (25) educational counselors who are not members of the current study sample. The calculation of the stability coefficient was determined using the internal consistency method - Kronbach Alpha, reaching $(0.85)$, which is acceptable for the purposes of this study.

\subsubsection{The Scale of Professional Competence}

The two researchers developed the professional competence scale through consulting related literature [7]. The scale consists initially of (30) paragraphs which are answered to in accordance with Likert's five-layer scale (very large, to a large degree, to a medium degree, to a low degree, very low). The following measure has been adopted to determine the mean rating: The mean of $(2.33$ and lower) got low degree; the mean of (234-3.66) got medium degree; the mean of (3.67 and higher) got high degree.

\subsubsection{Validity of the Scale}

The researchers verified the validity of the scale through asking several arbitrators with high experience in the field of psychological counseling and educational psychology to judge the extent to which the paragraphs are related to the scale and whether the language of the scale is appropriate or not. According to the arbitrators, (6) paragraphs are reworded, while (3) paragraphs are deleted for lack of relevance to the study tool. This means that the final number of paragraphs of the scale is (27).

\subsubsection{Stability of the Scale}

To verify the stability of the scale, it was applied to a pilot sample consisting of (25) educational counselors who are not members of the current study sample. The calculation of the stability coefficient was determined using the internal consistency method - Kronbach Alpha, reaching (0.91), which is acceptable for the purposes of this study.

\section{Results and Discussion}

Before starting to present and discuss the results of the study, the means and standard deviations of the of self-efficacy and professional competence degree of the educational counselors were extracted, showing that the degree of self- efficacy of the educational counselors came to an average degree as the mean of the their response reached (3.59) of the total degree. The researchers explain this finding as the educational counselors have effective personal characteristics because they bear a good degree of responsibility due to their university qualifications in psychological guidance and educational guidance. And thus, this gives them specific abilities to solve the problems of the counseled and help them reconcile psychologically and socially.

The nature of the guidance profession requires an acceptable degree of self- efficacy so that the psychological counselor can achieve the guiding tasks assigned to him / her, and respectively achieving the objectives of the educational process. A good sense of self- efficacy by good educational counselors is essential to be reflected on their counseled. The task of creating an encouraging learning environment lies with the educational counselor by providing the necessary assistance to the counseled to solve their problems, whether they are educational, social or psychological problems, and this requires highly effective educational counselors.

However, the degree of professional competence of educational counselors was high as the mean of the response was (3.76) of the total degree. The motivation of this segment of educators to provide a distinctive and efficient performance may be their sense of sincere belonging to the society in which they live, and this can also be explained by the fact that despite the difficult circumstances of life, these conditions have created a situation of challenge, determination and efficiency in the guiding performance. The guidance profession has become a socially and economically acceptable profession, as the new changes may be a factor in increasing the motivation and adequacy of educational mentors towards their profession and increasing psychological satisfaction with the profession. In addition, the theoretical framework indicates that motives are the force that drives individuals to perform their functions, as high levels of motivation result in a sense of individuals' sufficiency to accomplish tasks to the fullest extent of their abilities. Unlikely, low levels of motivation lead to poor performance and turnover. 
The drive to work will create a constant desire to strive for success and to achieve the least amount of time, effort and best performance.

Question 1: Does the degree of self-efficacy of educational counselors vary according to the variables of the gender of the counselor, the stage of study, and the number of years of experience?

To answer this question, a triangular contrast analysis (3 WAY-ANOVA) was used, and table 2 shows this.

Table 2 shows that there are no statistically significant differences in the degree of self-efficacy of educational counselors depending on the variables of gender and the school stage. The researchers explain the lack of differences due to the gender variable because of the guides' awareness of the importance of the guiding skills that help them achieve their role effectively, positively reflected on overcoming the differences between male and female counselors. Thus, they have similar levels of self-efficacy in indicative skills. The researchers also explain the lack of significant differences due to the change in the school stage because the educational counselors in schools are those with scientific qualifications in the disciplines of psychological trauma, mental health, and psychology, having knowledge of modern theories in guidance, the ability to provide Guidance services regardless of the nature of the study stage (primary or secondary). As well, the results also indicated that there were statistically significant differences in the degree of self-efficacy of educational counselors due to the change in the number of years of experience. To show the statistical significance of the differences, dimensional comparisons were used in Shefeeh's method as in table 3.

Table 3 shows statistically significant differences between the experience group of (10-19 years) and the experience group of (more than 20 years) that go for the experience group of (10-19 years). This is because experienced educational counselors of (10-19 years) category are keener and adherer to carry out the tasks assigned to them, caring more about communicating with parents and the local community. While the experienced educational counselors of (20 years and older) category have fewer career ambitions, since the educational counselor is not allowed to promote in the career ladder like the teacher, the counselor has a very limited chance of promotion, making kind of frustration and professional combustion as he / she remains named educational counselor until the end of his / her service.

Question 2: Does the degree of professional competence of educational counselors vary according to the variables of the gender of the counselor, the stage of study, and the number of years of experience?

To answer this question, a triangular contrast analysis (3 WAY-ANOVA)was used as shown in Table 4.

Table 2. Analysis of the triangular contrast analysis (3 WAY-ANOVA) of the impact of gender, the school stage, and the number of years of experience on the degree of self-efficacy

\begin{tabular}{|c|c|c|c|c|c|}
\hline Source of variance & Squares total & Freedom scores & Squares Average & Self-efficacy value & Statistical significance \\
\hline Gender & .338 & 1 & .338 & 1.962 & .165 \\
\hline School stage & .067 & 1 & .067 & .389 & .535 \\
\hline The number of experience years & 2.564 & 2 & 1.282 & 7.437 & .001 \\
\hline Error & 14.307 & 83 & .172 & & \\
\hline Total & 17.125 & $\mathbf{8 7}$ & & & \\
\hline
\end{tabular}

Table 3. Dimensional comparisons in Shefeeh's method of the effect of the number of years of experience on the degree of self-efficacy

\begin{tabular}{|c|c|c|c|c|c|}
\hline \multirow{3}{*}{ Self-efficacy } & The experience years number & The mean & Less than 10 years & $(10-19)$ years & 20 years and more \\
\cline { 2 - 6 } & Less than 10 years & 3.56 & & \\
\cline { 2 - 5 } & $(10-19)$ years & 3.77 & .21 & .16 & $.37 *$ \\
\hline
\end{tabular}


Table 4. The 3-WAY-ANOVA analysis of the impact of gender, the school stage, and the number of experience years on the degree of professional competence

\begin{tabular}{|c|c|c|c|c|c|}
\hline Source of variation & Squares total & Freedom scores & Squares average & Self-efficacy value & statistical significance \\
\hline Gender & .816 & 1 & .816 & 2.385 & .126 \\
\hline School Stage & .350 & 1 & .350 & 1.023 & .315 \\
\hline Experience years & 2.414 & 2 & 1.207 & 3.529 & .034 \\
\hline Error & 28.383 & 83 & .342 & & \\
\hline Total & $\mathbf{3 2 . 2 5 9}$ & $\mathbf{8 7}$ & & & \\
\hline
\end{tabular}

Table 5. The dimensional comparisons (of Shefeeh's method) for the impact of experience years on the degree of professional competence

\begin{tabular}{|c|c|c|c|c|c|}
\hline & Experience years & The mean & Less than 10 years & $10-19$ years & 20 years and more \\
\hline \multirow{3}{*}{ Self-efficacy } & Less than 10 years & 3.85 & & & \\
\cline { 2 - 6 } & $10-19$ years & 3.88 & .03 & & \\
\cline { 2 - 6 } & More than 20 years & 3.54 & .31 & $* .35$ & \\
\hline
\end{tabular}

Table 6. The results of the analysis of the simple regression of the effect of self-efficacy on professional competence as follows

\begin{tabular}{|c|c|c|c|c|c|}
\hline Independent variable & $\begin{array}{c}\text { Link Coefficient } \\
\text { of R }\end{array}$ & $\begin{array}{c}\text { Selection } \\
\text { Coefficient of R }\end{array}$ & $\begin{array}{c}\text { B } \\
\text { Factor }\end{array}$ & $\begin{array}{c}\text { Self-efficacy } \\
\text { Value }\end{array}$ & $\begin{array}{c}\text { statistical } \\
\text { significance }\end{array}$ \\
\hline $\begin{array}{c}\text { Impact of self-efficacy on } \\
\text { professional competence }\end{array}$ & $.775(\mathrm{a})$ & .600 & 1.063 & 128.989 & $.000(\mathrm{a})$ \\
\hline
\end{tabular}

It is clarified in table 4 that there are no statistically significant differences with respect to the degree of professional competence of educational counselors depending on the variables of gender and the school stage. The researchers explain the lack of significant differences due to the gender variable because the counselors are academically and professionally qualified, and they were appointed to a unified program in which the gender differences are not included in terms of requirements. And the effective counselor in the school performs the tasks assigned to him / her issued by the Ministry of Education and education regardless of gender. The researchers attribute the lack of significant differences in the variable of the study stage to the academic and professional preparation of the counselors which is done to all counselors at the same level despite the difference in the study age of the school in which they work. Moreover, the guidance profession has its foundations and principles, which do not vary according to the developing stage since the difference is not in substance, but in simple formalities. The results also indicated that there were statistically significant differences in the degree of professional competence of educational counselors due to the change in the number of years of experience. To show the statistical significance of the differences, dimensional comparisons were used in (Sheffeh's method) as in table 5 .

Table 5 shows statistically significant differences between the experience group of (10-19 years) and the experience group of (20 years and over) that go for the experience group of (10-19 years). This is because experienced educational counselors of (10-19 years) have the motivation and ambition to improve the work, seeking acceptance and approval from both the school administration and the local community. Unlike the experienced counselors of (20 years and older) who have less professional ambition, because of their arrival to the status of frustration and professional combustion, and the opportunities for promotion for mentors are very limited.

Question 3: Is there a relationship between self-efficacy and professional competence among educational counselors?

To answer this question, a simple regression analysis was used, and table 6 shows this.

Table 6 shows that the interpreted variation was $(0.600)$ which indicates that self-efficacy is associated with the value $(60 \%)$ The disparity in professional competence has also been shown to have a statistically positive effect on the effectiveness of the self, with a value of 128,989 (and statistically significant figures $(0.000)$. The researchers believe that this result is logical because the more the individual feels self-efficacy, the higher the professional competence of the educational counselor is. This result is consistent with the theoretical framework of the study since self-efficacy and professional competence factors co-operate in formulating the concept of motivation which is, in turns, considered to be one of the affecting factors on the individual's self-efficacy. Bandura has expressed self-efficacy as a force that explains the latent motives behind individual's behavior in different spheres of life. In addition, the perception of self-efficacy contributes significantly to understanding and determining the causes of the diverse range of individual's conduct, and his /her behavior of the initiative and perseverance for achievement. Through theories that dealt with professional competence, we note the emphasis on motives as the driving force of the behavior of individuals to perform their functions. High levels of motivation result in improved functional performance and, consequently, a higher level of 
professional competence. Bandura (1989) [11] adds that individuals' perception of their own efficacy influences the plans they make for themselves as those who are with a high sense of self-efficacy make successful plans to help them achieve goals and improve their professional competence, but those who judge themselves as ineffective are more inclined to get failed plans and poor performance.

\section{Conclusions}

The current study found that the degree of self-efficacy of educational counselors was 'moderate', and that the degree of professional competence of educational counselors was 'high'. The results also found that there were no statistically significant differences in the degree of self-efficacy and professional competence of the counselors according to the gender and study stage variables. . As well, there were differences in the degree of self-efficacy and professional competence regarding the variable of number of experience years that went for the experience years of (10_19) category. The current study also found a statistically positive effect between the degree of self-efficacy and professional competence of educational counselors.

\section{Recommendations}

In light of the findings, the researchers recommend holding training courses to learn about recent experiences in psychological and educational guidance in order to develop and enhance professional competence among educational counselors. As well, they recommend conducting further studies on self-efficacy and professional competence, in light of variables that are not addressed in the current study, such as the economic level and scientific qualification. Also, there should be an experimental study that aims to design guiding programs to improve the degree of self-efficacy and professionalism of educational counselors.

\section{REFERENCES}

[1] Ahmed, A. (1994). School Supervision. Egypt: Dar al-Fikr al-Nari

[2] Al-Asadi, S. (2001). Identifying the Contributions of the Educational Counsellor in the Field of Professional Guidance. Journal of Educational and Psychological Sciences, No. (41).

[3] Al-Daraji, H. (2010). Self-Efficacy and Its Relation to Satisfaction with the Counseling of Educational Counselors in Baghdad Governorate. Journal of the Faculty of Basic Education, 16 (66).
[4] Al-Harashsha, S. (2001). Evaluation of the Professional Competence of the Jordanian Educational Counselors in the Counseling Interview in the Light of Counseling Theories and Training Programs. Dissertation unpublished $\mathrm{PhD}$, Faculty of Education, University of Baghdad.

[5] Al-Morshedi, B. and Al-Saheel, R. (2000). Introduction to Psychological Counseling. Kuwait: Al Falah Library for Publishing and Distribution.

[6] Al-Nashi, W. (2005). Emotional Intelligence and Its Relation to Self-Efficacy among Teachers. Unpublished master's thesis, Faculty of Arts, Mustansiriya University.

[7] Al-Sarrai, Z. (2011). Alert Personality and Its Relationship with the Professional Competence of Journalists. Master Thesis unpublished, Faculty of Arts, University of Baghdad.

[8] Al-Shurafa, A. (2011). The professional Self of Psychological Counselors in the Educational Counseling Work in Gaza Strip. Unpublished Master Thesis, Islamic University, Gaza.

[9] Al-Yaffi, A and Al-Sheikh, N. (2005). The Functions of the Educational Counsellor and His/Her Competencies in the State of Qatar in Light of the Directives of Modern Educational Supervision, Journal of Education, 8 (15), the Egyptian Association for Comparative Education.

[10] Bandura, A. Nancy, E. A. \& Janice, B. (1977). Cognitive Processes Mediating Behavior Change. Journal of Personality and Social Psychology, 35 (3), 125-130.

[11] Bandura, A. (1989). Regulation of Cognitive Processes through Perceived Self-Efficacy. Developmental Psychology, 25 (5), 729 - 735.

[12] Bandura, A. (1994). Self-Efficacy. in V.S. Ramachaudran Encyclopedia of Human Behavior, Vol. 4. New York, Acamic Press. Education / mfp / Banency.

[13] Devis, K. (1983). Human Behavior at work organizational Behavior new Deini. MC Graw Hill.

[14] Fumawi, H. and Reza, A. (2009). Psychological Pressures in the Field of Work and Life Psychological Confrontations for the Sake of Human Development. Amman: Dar Safa.

[15] Hashemi, A. (2009): Guidance and Psychological Counseling (Preventive Mental health). Jeddah. KSA. .

[16] Hay, M. (1991). Task Per for mance A.S. Function of Self Efficacy, Attribution, and Task Preview information. D. A 1, 52-4B, Pzz 36.

[17] Obaid, S. (2006). Self-Efficacy and Its Relation to the Psychological Stability of Educational Counselors. Master Thesis unpublished, Faculty of Education, University of Mustansiriya.

[18] Pajares, K. (1997). Gender and Perceived Self Efficacy in Self-Regulated Learning. Theory into Practice.

[19] Razak, M. (2003). The Effectiveness of the Program of Emotional Enlightenment in Developing Emotional Intelligence for Students at the Faculty of Education in Taif. Um Al Qura Journal of Educational, Social and Human Sciences, 15 (2).

[20] Said, A. (2005). The Impact of Self-Affirmation in 
Developing Self-Efficacy and Social Anxiety at the University. Unpublished doctoral thesis, Faculty of Education, University of Mustansiriya.

[21] Schunk, D. (1981) .Modeling and Attitudes Effects on Children Achievement: A Self-Efficacy Analysis. Journal of Education Psychology, 73 (1), 93- 105.

[22] Tawfiq, M. (2002). Self-Efficacy and Its Relation to the Level of Ambition and Motivation of Achievement within General Secondary Students and Technical Secondary Students. Unpublished MA, Institute of Studies and Research, University of Baghdad.

[23] Tishtosh, R., Sherifin, A. and Beni Mustafa, M. (2014). Counseling Skills of Trained Counselors as Recognized by Trained Counselors and Co-Counselors. Journal of the University of Hebron Research, 9 (2), 209-240.

[24] Department of General Statistics. (2019). Population statistics. Retrieved from http://dosweb.dos.gov.jo/ar/ on 21st November 2011.

[25] Ministry of Education. (2019). Statistical report. Retrieved from http://moe.gov.jo/ on 21st of November 2019. 